\title{
Fall Protection Training: A Case Study Using Cbt for Latino Construction Workers
}

\author{
David P Gilkey1*, Carla Lopez Del Puerto ${ }^{2}$, Megan R Miller², Carlos Evia ${ }^{3}$ and Carla Lopez Del Puertoisnow \\ ${ }^{1}$ Environmental and Radiological Health Sciences, Colorado State University, USA \\ ${ }^{2}$ Department of Construction Management, Colorado State University, USA \\ ${ }^{3}$ Department of English and Center for Innovation in Construction Safety and Health Research, Poly Technical University, USA \\ ${ }^{4}$ Department of Civil Engineering, The University of Puerto Rico, USA
}

Submission: December 5, 2017; Published: December 21, 2017

*Corresponding author: David P Gilkey, Environmental and Radiological Health Sciences at Colorado State University, USA, Tel: 80523-186; Email: dgilkey@colostate.edu

\begin{abstract}
Latino construction workers are at an increased risk of worksite injuries and fatalities due to language, cultural barriers, and ineffective training. This case-study investigated computer-based video training (CBT) for scaffold safety. The CBT training was developed using a participatory approach involving direct input from Latino roofers and framers. This paper focuses on evaluation-improvement of training that combined workers' ideas of a safe work environment with OSHA standards. Researchers investigated the appropriateness and effectiveness of a brief CBT presentation addressing fall protection and scaffold use among Latino roofers. The results indicated that Latino construction workers at a roofing company in Colorado gained knowledge ( $\mathrm{p}$-value $<0.05$ ) and liked the use of a culturally appropriate educational video as a method of training. The positive reactions to the training intervention are encouraging and support information and communication technologies (ICTs) for training Latino construction workers with lessons learned for follow-up training and evaluation.
\end{abstract}

Keywords: Construction Safety; Computer Based Training; Latino Construction Workers; Training In Spanish

\section{Introduction}

The construction industry employed 9.1 million workers in 2010 and contributed $3.5 \%$ of the gross national product to the US economy (Center for Construction Research and training Construction work has remained a high-hazard industry with 13,882 workers killed in the course of employment between 1992 and 2010 [1] reported that between 2003 and 2010, 1,917 residential construction workers died in the US due to falls. In 2010, 802 construction workers lost their lives with falls accounting for nearly half of all fatalities. A recent study by found that $32 \%$ fell to lower levels, $23 \%$ from ladders, and $18 \%$ from platforms. Exported that $48 \%$ of fatal falls evaluated were in residential construction and $16 \%$ were from scaffolds. Roofers (80\%) were at greatest risk compared to other specialty trades. Falls remain the leading cause of fatality for foreign-born Hispanic workers who are among those at highest risk. Latinos experience work-related injuries at twice the rate compared to non-Latino US workers and fatality rates $21 \%$ higher than their white peers, at a rate of 4.4 / 100,000 compared to $3.5 / 100,000$. There were an estimated 2.5 million Hispanics comprising 27\% of the construction workforce in the U.S., yet they made up 33\% of all fall related fatalities between 2003 and 2010.

All workers in the construction industry face the inherent risks for injury regardless of their ethnicity [2] nevertheless, language, cultural barriers $[3,4]$ and ineffective training can further diminish workers' understanding and reaction to potential hazards, degrade work safe behaviors and limit use of effective controls [5-8] found that peer-led participatory safety training for Latino day-laborers significantly improved work safe behaviors. The training experience positively affected their attitudes toward safety training, use of safety materials, self-protective behaviors such as increasing their use of PPE and the willingness to engage their employer around safety issues [9] also found significant improvements with behavioral change among 446 Latino workers trained over three years. Their study identified improved evaluation scores in knowledge gains, improved hazard identification skills, self-efficacy and sustainable health and safety activities. This study included $87 \%$ foreign-borne Latinos from Mexico who participated in 25 
OSHA 10-hour training sessions. Significant knowledge gains were found relating to the importance of guard rails to mitigate fall hazards as well as other safety hazards. These investigators also identified the lack of rigorous application and evaluation of instruments when assessing Latino workers.

The most common approach to training Latino construction workers in the US is to translate English materials into Spanish and then use those materials in sessions led by bilingual trainers [10]. However, direct translations methods may lead to inaccuracies [11] that can be misleading and even have fatal outcomes [12]. Ineffective safety training is one of the leading contributions to workplace accidents for Latino construction workers, and the construction industry lacks appropriate tools to effectively educate Spanish-speaking workers about fall protection and other workplace hazards $[13,14]$. Other than agriculture, the construction industry has the highest proportion of Latino workers in the U.S. [15], making the construction industry a high priority for safety research and translation to practice. Many Latino construction workers are classified as laborers, accounting for more than $38 \%$ of all laborers in the industry Olbina, Hinze, \& Ruben.

The five most common trades for Latinos working in construction include carpentry, concrete, painting, drywall installation, and roofing Good rum [16,17]. While Latino workers continue to account for a disproportionate number of occupational injuries in the construction industry there remains a paucity of research involving Latino workers [18] Brunette MJ There is a significant need to understand and address the disparity between working ethnic groups [19] found that Latinos experienced a 4.4 / 100,000 fatality rate (RF) overall and more than a two-fold increase for the construction sector with a FR of 10.9 / 100,000. Their data yielded an odds ratio of 1.92 (CI 1.33-2.75) for the Latino worker to experience falls. Research is needed to evaluate and identify effective training strategies. Proof of training effectiveness remains difficult to measure however, Forst et al. states intent to change, increase in knowledge and behavioral change are positive evidence for effectiveness. Only long-term follow up and actual injury and fatality data can prove effectiveness. As reported in previous publications (Evia ; Evia \& Patriarca,), this study has the overarching purpose of bridging the gap between traditionallytranslated materials developed originally in English and actual information needs and preferences of Latino construction workers. Its main approach was to incorporate elements of participatory design (PD) to understand the intended audience and empower workers to take an active role as contributors in the video's development and evaluation. As a research methodology, PD is based on labor-analysis ideas originally used in the 1970 s by Norwegian unions looking for a more democratic approach to the design of workplace tools. Its fundamental idea is "the involvement of workers, as users of technology, in the design of the tools they are using in their work place" $[20,21]$ identifies three key criteria for evaluating PD projects and interventions: (a) quality of life for workers, (b) collaborative development, and (c) iterative process.

The purpose of this paper is to report on the evaluation of a CBT session on the topic of safety when using scaffolds on construction sites. Aimed at Spanish-speaking construction workers, the video was developed in a participatory design approach, involving direct input from Latino roofers and framers. Originally developed with input from Latino construction workers in Virginia the CBT video combined workers' ideas of a safe work environment involving scaffolds with OSHA standards and recommendations. Following the criteria for participatory design proposed by Spinuzzi, this paper focuses on the iterative process of evaluation-improvement of the training video. After incorporating additional feedback from Latino construction workers, and with enhanced representation of OSHA standards, this follow-up case study investigated the appropriateness and effectiveness of the video enhanced CBT addressing fall protection and scaffold use among Latino roofers in the Denver metro area of Colorado.

\section{Methods}

The first version of the training video used stop-motion animation with construction figurines from Fisher Price's Little People (with proper authorization from the toymaker). Previous work (Evia ; Evia \& Patriarca) reports on that version's evaluation and effectiveness. However, during training sessions and expert reviews conducted in Virginia, Massachusetts, and North Carolina in 2012 and 2013, new feedback emphasized areas for improvement in the video's iterative development, which included the following:

a) Although workers rated the video's balance of entertainment and training content as appropriate, contractors and supervisors were concerned about the use of Fisher Price toys when representing serious work place hazards.

b) The Fisher Price toys could not move their "arms" or "legs." Workers pointed out the need of having figurines that looked more anthropomorphic and could be shown climbing stairs and holding objects.

c) The video represented the workers' vision and in some instances was not exactly in compliance with OSHA's 29 CFR 1926 regulations for construction.

d) The research team needed further evaluation with a larger number of workers.

To address those areas for improvement, the team developed a new version of the video, which respected the original workerdeveloped script but ensured OSHA compliance. Instead of Fisher Price toys, the revised video features stop-motion animation with wooden manikins (Figure 1). 


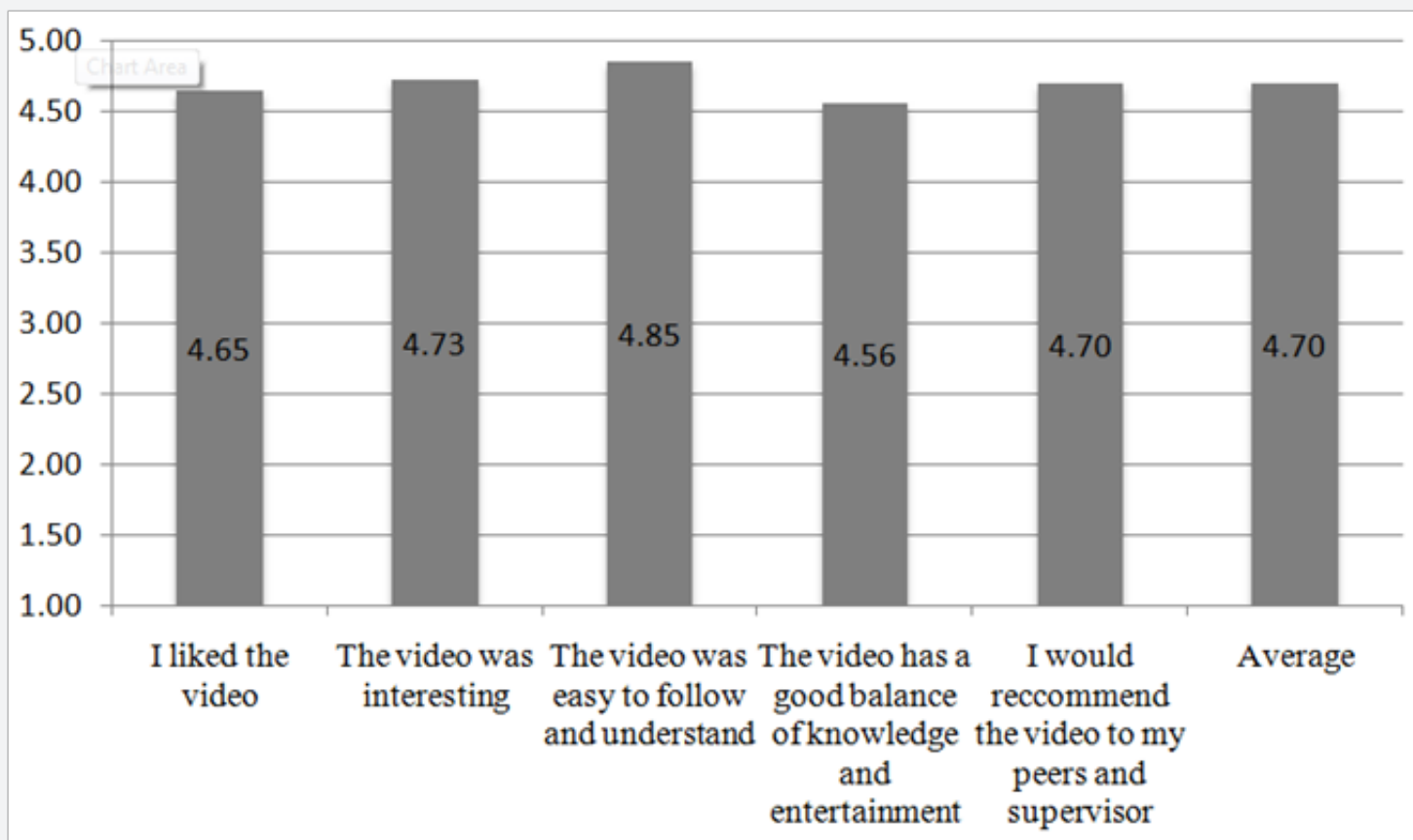

Figure 1: Participant Reaction to Video Appropriateness.

The evaluation strategy for this study used a mixed methods research design with concurrent triangulation strategy that utilizes both qualitative and quantitative evaluation [22,23]. The concurrent triangulation approach allows the researchers to collect both qualitative and quantitative data concurrently to determine if there is convergence, differences or a combination of both. The mixed methods approach was used to strengthening the overall study (Creswell \& Plano-Clark). The methodological approach incorporated the use of a survey instrument, educational CBT video intervention and pre and post written testing consisting of yes or no questions. There were questions with discrete, categorical and open-ended responses which examined the participants' demographic information and their reactions to the video. The responses were gathered via self-report survey sad ministered by a field researcher. The overall intent was to evaluate the CBT platform for effective communication, the participants' reactions, and relevance for Latino workers, cultural appropriateness, and knowledge gain. It also provided insight into whether or not the workers' demographics influenced the learning outcomes of the intervention and if evaluation methods were appropriate to detect changes in learning. Participation in this study was voluntary. Participants were recruited through convenience sampling and were employees of a roofing company in Northern Colorado that agreed to participate in this study. The only workers excluded from participating were those who did not speak Spanish. Each participant received a five-dollar cash incentive and was required to complete a verification form, which consisted of subject's name, signature and the date. The form was kept separate from the surveys to limit the risk of the participants' identities from being revealed. The survey consisted of 19 questions pertaining to the participants' demographics, 14 questions inquired about their reactions to the video and its cultural relevance, and 10technical questions with multiple choices about fall protection and scaffold use. Participants were asked to respond to each technical item either positively or negatively. Demographic questions addressed age, main language, trade, country of origin, number of years in the industry, amount of fall protection training at work, and if the training was in the participant's main language. Seventeen of the 19 demographic questions were multiple choice and two were open ended. Ten of the questions evaluated the participants' reactions to the video and its cultural relevance was multiple choices and four were open ended questions. The multiple choice questions used a Like rating scale from one to five, with one being when participants totally disagreed and five being when they totally agreed with the corresponding statement. When an open-ended question was used, individual responses were grouped and assigned a coded number. For example, if the survey question, "In what country were you born?" was answered with "Mexico," this response was coded as " 1 ." If any other participant provided "Mexico" on their survey, the same number was assigned to that response. This process was repeated until every response received a code number. The surveys were coded; the results were manually entered into a Microsoft Excel spreadsheet. The raw data were moved to Stat Plus: Mac ${ }^{\mathrm{T}}$ for analysis. Data analysis included descriptive statistics and frequencies to determine means, ranges and proportions. The paired two-sample, t-test statistic was used to evaluate variance in pre and post intervention testing and knowledge gains. 
Results

Table 1: Roofers by Age, Years in Construction in Country of Origin and Highest academic degree.

\begin{tabular}{|c|c|c|}
\hline Age & $\mathbf{N}$ & $(\%)$ \\
\hline 30 or younger & 12 & $30 \%$ \\
\hline Between 31 and 40 & 19 & $48 \%$ \\
\hline Between 41 and 50 & 7 & $17 \%$ \\
\hline Older than 50 & 2 & $5 \%$ \\
\hline \multicolumn{3}{|l|}{ Years in construction in country of origin } \\
\hline I didn't work in construction & 15 & $40 \%$ \\
\hline Less than a year & 2 & $6 \%$ \\
\hline $1-3$ years & 3 & $8 \%$ \\
\hline 4-6 years & 4 & $11 \%$ \\
\hline More than 7 years & 13 & $35 \%$ \\
\hline \multicolumn{3}{|l|}{ Highest academic degree } \\
\hline Attended elementary school, did not graduate & 3 & $8 \%$ \\
\hline Graduated elementary school & 5 & $13 \%$ \\
\hline Attended middle school, did not graduate & 2 & $5 \%$ \\
\hline Graduated middle school & 13 & $33 \%$ \\
\hline Attended high school, did not graduate & 9 & $24 \%$ \\
\hline Graduated high school & 3 & $8 \%$ \\
\hline Vocational or technical school & 1 & $2 \%$ \\
\hline Attended a University, did not graduate & 2 & $5 \%$ \\
\hline Graduated from a University & 1 & $2 \%$ \\
\hline
\end{tabular}

The survey was completed by 45 Latino roofers. One hundred percent of the study participants reported their gender as male. When asked to provide their age, the participants were given four possible answers: 30 or younger, between 31 and 40 , between 41 and 50 and older than 50 years of age. Of the 40 participants who responded, $78 \%$ reported they were 40 years old or younger (Table 1 ). When asked to provide their primary

or main language, $98 \%$ reported that their main language was Spanish. Only $2 \%$ of the study population identified English as their main language. Of the 40 participants who responded when asked to identify their country of origin, $93 \%$ reported that they were born in Mexico; $5 \%$ reported they were born in the US and $2 \%$ were born in Bolivia.

Table 2: Hours of Safety Training in the Last Year

\begin{tabular}{|c|c|c|}
\hline Hours of Safety Training & N & (\%) \\
\hline 0 hours of safety training & 1 & 0 \\
\hline 1 hours of safety training & 1 & $2 \%$ \\
\hline 2 hours of safety training & 1 & $2 \%$ \\
\hline 3 hours of safety training & 1 & $2 \%$ \\
\hline 4 hours of safety training & 39 & $92 \%$ \\
\hline 5 hours of safety training & & $2 \%$ \\
\hline
\end{tabular}

In addition to providing their country of origin, participants provided the number of years they had lived in the US. Possible responses were: less than a year, 1-3 years, 4-6 years and more than 7 years. Of the 37 responding, $92 \%$ reported they had lived in the US for more than seven years and the remaining $8 \%$ had lived in the US between four and six years. Forty-six percent reported that they had less than one year or no construction experience in their country of origin (Table 2). Eighteen percent indicated that they had between one and 6 years of construction experience in their country of origin and 35\% indicated that they had more than 7 years of construction experience in their country of origin. When asked about their highest academic degree, $83 \%$ reported that they did not complete high school. The average education degree earned by the participants who responded was the completion of middle school. One hundred percent of the participants had received safety training in the past year and $92 \%$ had received more than five hours of training. Seventy-six percent indicated that the training they received included information on fall protection and scaffolding. When asked if the training they received was in their main language, 95 
$\%$ responded that the training was not presented in their main language. When asked to self-report their ability to speak and read English the participants were given a scale of 1-5 where: 5 were excellent and 1 was poor. Forty percent reported their ability to speak English as poor. In response to their ability to read Spanish, $37 \%$ responded that their ability to read Spanish was excellent. The remaining responses varied equally from regular to very good.

\section{a. Video Reactions}

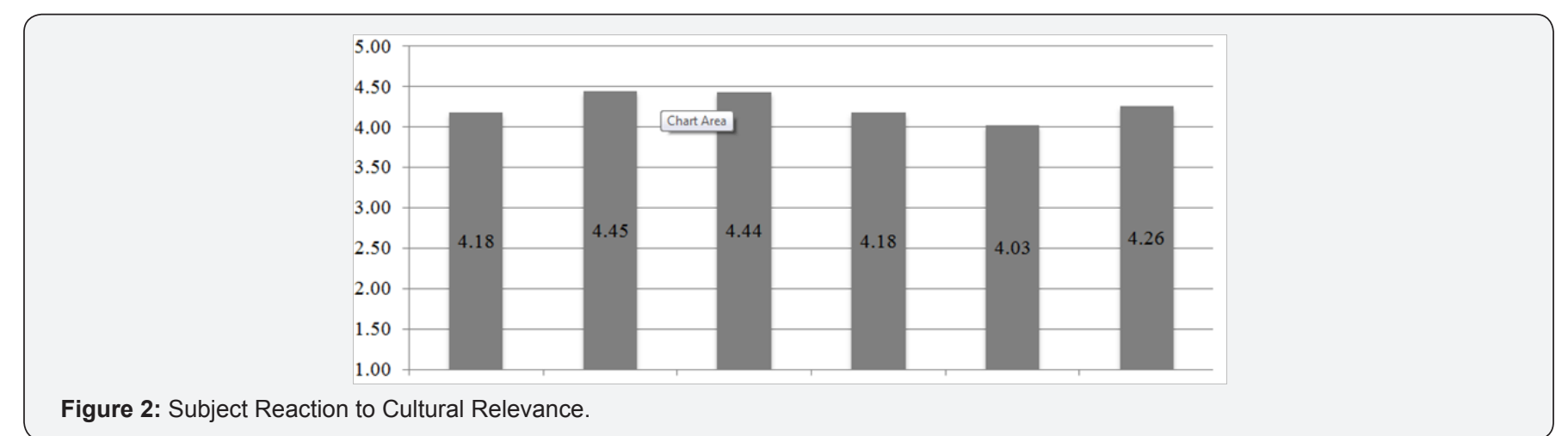

Figure 2: Subject Reaction to Cultural Relevance.

Section II of the survey focused on the participants' reactions to the video (Figure 2). The participants were given a rating Liker scale of $5=$ totally agree, $4=$ Agree, $3=$ neither agree nor disagree, 2 = Disagree or 1 = totally disagree. When asked if they, "Liked the video", 41 participants provided responses; $93 \%$ agreed with the statement and seven percent neither agreed nor disagreed. Overall, the participants agreed with the statement, rating the video an average score of 4.7 out of a possible 5.0. Ninety-five percent agreed with the statement "The video was interesting," and $5 \%$ neither agreed nor disagreed. On the given scale of 1-5 points, the participants scored the video an average of 4.7 out of 5.0.0f the 40 participants who provided responses to whether "The video was easy to follow and understand,"100 $\%$ agreed or totally agreed with an average score of 4.85 out of a possible 5.0.Thirty-nine participants responded to whether they agreed with the statement "The video had a good balance of knowledge and entertainment." The majority (93\%) of the participants agreed, 2\% neither agreed nor disagreed and 5\% disagreed. Overall the participants gave the video an average score of 4.6/5.0 for balance. The final question used to assess the participants' reaction to the video inquired as to whether or not they would recommend the video to their peers or supervisors. Forty-two participants responded giving the video a score of 4.7/5.0. Ninety-five percent of the participants agreed they would recommend the video. The remaining $5 \%$ of the participants neither agreed nor disagreed.

Following the completion of the video CBT, the participants were asked to respond to three questions: what did you like the most about the video?; what did you like least about the video? And what would you change about the video? Thirtynine participants provided written responses describing what they liked most about the video; 10 participants simply stated that they liked "all" of the video. Eleven participants liked the safety content of the video, providing answers such as "the safety instructions," or that they liked "the way (characters in the video) always talks about safety at work," how "everyone speaks of job safety," and the way the characters "speak up about safety." Other noteworthy answers included "(the video is) easy to understand with humor" and that "everything was in my language."The second written question provided written answers on what the participants liked the least about the video. Of the 27 participants who responded, four stated they did not dislike anything about the video responding with "nothing," I "liked everything" or that "it seemed appropriate." Another common response was "volume" or "audio," as they did not like the volume of the video and thought it was not loud enough for the participants to hear from a distance. One participant disliked the length of the video responding that it was "very short." Another participant disliked that the video "only talked about scaffolding," and one participant liked the "worker insecurity" the least. The most common topic in the answers provided by the participants on what they liked the least about the video was in reference to the characters. Seven participants disliked the "characters" in general, the "accent" of the characters or their "emotions." Twenty-three subjects indicated that they would change "nothing" about the video while five participants would change the "characters" either in general or so "that they move their bodies" or show "respect" and "not use nicknames." Another participant would change the video to make it "longer" by adding "a little more on stairs."

\section{b. Cultural Relevance}

The third section of the survey focused on the cultural relevance of the fall protection video using the same Liker scale as the video reactions section. Of the 38 participants who provided responses to whether "The characters in the video were like my colleagues and me," $79 \%$ of the participants agreed. Thirteen percent of the participants neither agreed nor disagreed, and $8 \%$ disagreed. Overall, the participants agreed with the statement, rating the video an average score of 4.2 out of a possible 5.0 (Figure 2). When asked if the "events in 


\section{Juniper Online Journal of Public Health}

the video look like things that have happened to me at work", $87 \%$ agreed with the statement, while $10 \%$ neither agreed nor disagreed and $3 \%$ disagreed. Overall, the participants agreed with the statement, rating the video an average score of 4.5 out of a possible 5.0. Eighty-seven percent of the participants who responded to the statement "I have been or worked in setting like the ones represented in the video" agreed with the statement. Ten percent neither agreed nor disagreed and $3 \%$ disagreed. On the given scale of 1-5 points, the participants scored the video an average of 4.4 out of 5.0, expressing they had been or worked in a setting similar to the one portrayed in the video. When asked if "events from the video could take place this year", $79 \%$ agreed with the statement and $13 \%$ neither agreed nor disagreed. Eight percent of the participants reported that they totally disagreed. Overall, the participants agreed with the statement, rating the video an average score of 4.2 out of a possible 5.0.The final question intended to determine if the video was culturally relevant provided whether or not the participants agreed that "the characters in the video talked like my colleagues and me." Thirty-eight participants responded, giving the video a score of 4.0/5.0. Of the 38 responses, $68 \%$ of the participants agreed the characters talked like them and their colleagues, while $18 \%$ neither agreed nor disagreed and $14 \%$ disagreed. At the end of the survey each participant was given the opportunity to provide additional comments. All of the participants who provided more input gave positive and constructive responses. One participant shared that they thought the video was "good for orientation" and another asked for "more examples."

\section{c. Pre and Post Fall Protection and Scaffold Use}

To evaluate knowledge gain on the subject of scaffold safety, the evaluation process included pre and post-video tests. The technical questions asked were directly associated with OSHA regulations. The questions included in the pre- and post-video test were identical. A total of 41 questions were asked in nine areas of fall protection and scaffold safety. The breadth of question represented common Positive differences in pre and post scores were seen in all technical areas with significant differences, P-value $<0.05$, in three questions relating to strong winds ( $p$-value $<0.05$ ), scaffold inspection ( $p$-value 0.03 ), and guard rails ( $p$-value $<0.05$ ). Overall, 20 questions showed gains in knowledge retention. Results also demonstrated diminished scores in one technical area and in 8 questions overall.

\section{Discussion}

The purpose of this pilot study was to develop, administer and evaluate the appropriateness and effectiveness of a CBT session comprised of five minute video training addressing fall protection and scaffold use among Latino roofers in the Denver metro area of Colorado. Results provide lessons learned and were helpful in characterizing Latino worker feedback, measuring parameters of effectiveness and garnering ideas for developing improved approaches for future safety training for Latino construction workers. Prior research has established the need to develop culturally- and language-appropriate safety training for Latino construction workers. The present study confirms the need to not only to develop culturally appropriate safety training but, also to consider alternative measurement methods and approaches used when evaluating training effectiveness among Latino construction workers. We now believe that this sub-group of construction workers, immigrant and/or US native born Latinos, may require alternative evaluation methods to detect changes in safety awareness and knowledge gains.

The results of the knowledge test indicate that participants have adequate technical knowledge about the OSHA regulations regarding fall prevention and that our training added little to their knowledge level. We believe that this may be an artifact and not be representative of actual knowledge gains but reflective of our measurement methods because of the mixture of small gains and losses in scores. Among most responses changes were non-existent, small and not significant. We found significant positive gains in only three technical areas. We also believe that while short duration training exposures have become popular in recent years, more research is needed to understand their true effectiveness on knowledge and behavior changes. As ICTs become increasing more popular for safety training among various industries, consideration and inclusion of cultural relevance must be included to maximize communication and adoption of safe work behaviors.

To achieve a more effective safety culture and learning, subjects need to feel that they can master the content, find value related to their jobs, be supported by their employer and that the assessment methods are accurate [24,25]. While reactions to the training were overwhelmingly positive, there had been no effort to obtain information regarding skill assessment feedback, expectancies or career and job attitudes that may have influenced subject's motivations to learn and to identify and develop optimal assessment methods. We believe that worker feedback about evaluation, oral interviews and administration of the pre and post assessment may have been a more effective evaluation method. Salas and Cannon-Bowers [26] stated that effective training needed key factors: Trainee contribution to the experience, engagement and participation and preparation to maximize the event.

This study evaluated 45 male Latino roofers working in Central and Northern Colorado. Our findings identify a maledominated trade and are consistent with published finding by others about the construction industry. Female's makeup less than $5 \%$ of laborers and less than $10 \%$ of all workers in the construction industry [27]. Our study identified $78 \%$ of roofers to be 40 years or younger, consistent with other investigators that reported $63 \%$ of the Latino workforce in the US was between 18 and 41 years of age [28]. The present study found that $93 \%$ of subjects reported that they were born in Mexico, 5\% reported they were born in the US, and 2\% were born in Bolivia. These findings were corroborated by other studies, which identified that approximately $60 \%$ of Latinos were born outside the US 
Forty-six percent reported that they had less than one year or no construction experience in their country of origin. Similar results were reported by Canales et al. that reported $51 \%$ of Latino workers had less than one year of experience in construction prior to moving to the US. Our study population revealed that 83\% had not completed high school and represented a higher proportion than reported by others at 41 .

An impressive $100 \%$ of participants reported that they had received safety training in the past year and $92 \%$ had received more than five hours of training. In addition, 76\% indicated the training included information on fall protection and scaffolding. This may also explain, in part, our lack of significant measurable gains in knowledge. As shown in the pre-test, participants had an adequate level of technical knowledge regarding OSHA regulations as they relate to fall prevention prior to our intervention. Results from our case study cannot be generalized, since this company may have a greater level of commitment to safety training than the usual roofing company. However, it was contrary to find that only $5 \%$ indicated that the training was presented in their main language. In our review of the literature, it was reported that $20 \%$ of safety trainings were delivered in the worker's native language other than English. Eighty-five percent of the roofers surveyed reported their ability to speak English as regular or bad. These results are somewhat consistent with other investigators that have identified over one-third of Latino construction workers only spoke Spanish. Nearly half of our study population reported their ability to read English as regular and $40 \%$ was bad. This finding is also consistent with published literature reports that $42 \%$ of foreign-born Latino workers cannot read English at all (Evia C). Ninety-eight percent of the participants in this study reported their main language as Spanish, when asked to rate their ability to read Spanish the average response was "very good." This finding is consistent with the published literature, which reports that a small, but significant, portion of Latino construction workers are illiterate in their own language and that individuals with lower literacy rates can read, but have difficulty in doing so [29].

The training platform, content, delivery, language and cultural compatibility were viewed as positive by nearly all respondents. Eleven participants liked the safety element of the video providing answers such as "the safety instructions," that they liked "the way they always talk about safety at work," how "everyone speaks of job safety," and the way the characters "speak up about safety." Other noteworthy answers included "easy to understand with humor" and that "everything was in my language."These responses about what they liked most about the video were consistent with prior research that suggested that on the job safety training be conducted in the subject's main language by a native speaker. Feedback was also positive, with nearly $80 \%$ of all respondents approving of the use of characters depicting Latino workers; "The characters in the video were like my colleagues and me."Overall, the participants agreed with the cultural relevance of the video an overall average score of 4.3 out of a possible 5.0.The results of this study were consistent with many of the findings in the published literature. One of the most common barriers to Latino construction worker safety training is the language barrier between the workers and their supervisors Canales, et al., which is directly related to the lack of formal education (Fox \& Livingston ; Brunette,)and low literacy rates. (Brunette) The educational training video utilized in this study was in Spanish in contrast to the $9 \%$ of the participants reported that the safety training they received in the last year was not presented in their main language.

Research conducted on the participants' reactions to ICTs supported our approach in this follow up study One additional training technique advocated was to create an intervention that would leave a lasting impression by including an element of entertainment [30]. This study implemented this suggestion and the participants' reactions supported this technique with the analysis of whether they like the video. The participants rated the video a score of $4.7 / 5.0$ in strong agreement to the statement "I liked the video" and backed their reactions with positive statements such as: I liked how the video was "easy to understand with humor" and "the way the characters always talk about safety at work."

\section{Limitations}

This study had numerous limitations. The study was conducted at a single company in northern Colorado and not randomly selected. The findings may not represent Latino construction workers at different companies or in other regions of the country. Colorado is home to approximately $2 \%$ of the Latino population in the US [31] making it implausible to make generalizations for the population as a whole. In addition, the study was limited by the small sample size $n=45$. A larger sample would have been more robust and representative of the population and industry. The sample was not random and obtained through convenience sampling using a company who had an existing relationship with the university. The company may represent a firm who provided more safety training than most firms and thus biased our result toward the null. There may be a better method for collecting the pre and post video data to account for the low literacy rate of the targeted population. Additional limitation in this study was the reliance on self-report responses by the participants and the potential presence of recall and information bias. This may also explain the absence of measurable differences in pre and post scores. Self-reported data that is not independently verified typically has a high chance of error as individuals may provide information they perceive as socially desirable [32-38].

\section{Conclusion}

This study demonstrates that Latino construction workers at a roofing company in Colorado liked the use of an educational video in CBT as a method of training and reported that the video was culturally appropriate. The positive reactions to the training 


\section{Juniper Online Journal of Public Health}

intervention are encouraging and support ICTs for training Latino construction workers. The written assessment methods did not support significant, broad and measurable knowledge gains as expected and represent a limitation in study methods. We believe that this is a major lesson learned and will drive our rationale for alternative assessment methods in future work. On average, the participants in this study self-reported their ability to read Spanish as "good;" however, we did not seek feedback in the development of the assessment tool or compare written to oral assessment methods. The ICTs used in this study elicited positive feedback from workers, demonstrated effective communication, was culturally appropriate and include valuable content for training Latino construction workers.

The number of Latinos workers in the construction industry is continually increasing and the need for effective training techniques is critical. Of paramount concern, is that the difference between effective and ineffective training may lead to unsafe behaviors that result in injury, pain and suffering, death and lost profits. Future studies should include the collaborative model advocated in previous publications including worker feedback in for all phases of training through evaluation. Future research should evaluate the use of verbally administered surveys, by a Spanish-speaking field investigators rather than the use of written versions. A text free means of collecting data such as verbal questions and responses has the potential to be a useful application for an illiterate or semiliterate participant in a study to provide their responses (Medhi, Sagar, \& Toyama). Our goal is to develop effective methods for training Latino construction workers and diminish their disproportionate injury and death.

\section{Acknowledgement}

This work was made possible in part by Grant Number T420H009229-04 from CDC NIOSH Mountain Plains Education and Research Center. Its contents are solely the responsibility of the authors and do not necessarily represent the official views of the CDC NIOSH and MAP ERC. This work was also sponsored by the Virginia Tech Innovation Center for Construction Safety and Health Research. Little People ${ }^{\circledR}$ Construction Worker figures used with permission of Fisher-Price Inc., East Aurora, New York 14052.

\section{References}

1. Dong XS, Wang X, Largay JA, Platner JW, Stafford E, et al. (2014) Fatal fall in the U.S. residential construction industry. American Journal of Internal Medicine.

2. Anderson J, T Hunting, KL, Welch LS (2000) Injury and Employment Patterns Among Hispanic Construction Workers. Journal of Occupational and Environmental Medicine 42(2): 176-186.

3. Gilkey D, Lopez del Puerto C, Chen P, Rosecrance J (2013) Comparative Analysis of Safety Culture and Risk Perceptions Among Latino and Non Latino Workers in the Construction Industry. Journal of Safety, Health and Environmental Research 9(2): 94-104.

4. Gilkey D, Lopez del Puerto C, Keefe T, Bigelow P, Herron, et al. (2012) Safety Culture in Residential Construction: Managers vs Workers.
Journal of Construction Engineering and Management (138): 10441052

5. Evia C, Patriarca A (2012) Beyond compliance: Participatory translation of safety communication for Latino construction workers. Journal of Business and Technical Communications 26: 340-367.

6. Olbina S, Hinze J, Ruben M (2011) Safety in Roofing: Practices of Contractors That Employ Hispanic Workers. Professional Safety p. 4452.

7. Evia C, Patriarca A (2012) Beyond compliance: Participatory translation of safety communication for Latino construction workers. Journal of Business and Technical Communications 26: 340-367.

8. Williams Q Ochsner M, Marshall E, Kimmel L, Martino C (2010) The impact of peer-led participatory health and safety training programs for Latino day laborers in construction. Journal of Safety Research 41: 253-261.

9. Forst L, Ahonen E, Zanomi J, Jolloway Beth, A, Oachner, et al. (2013) More than training: Community-Based participatory research to reduce injuries among Hispanic construction workers. American Journal of Industrial Medicine 56: 827-837.

10. Canales AR, Arbelaez M, Vasquez E, Aveiga F, Strong K, et al. (2009) Exploring Training Needs and Development of Construction Language Courses for American Supervisors and Hispanic Craft Workers. Journal of Construciton Engineering and Management 135(5): 387-396.

11. Brunette MJ (2005) Development of Educational and Training Materials on Safety and Health: Targeting Hispanic Workers in the Construction Industry. Family Community Health 28(3): 253-266.

12. Robotham G (2001) Safety Training That Works. American Society of Safety Engineers pp. 33-37.

13. ASSE (2004) Hispanic Outreach. Professional Safety p. 49.

14. Olbina S, Hinze J, Ruben M (2011) Safety in Roofing: Practices of Contractors That Employ Hispanic Workers. Professional Safety p. 4452.

15. Goodrum PM, Dai J (2005) Differences in Occupational Injuries, Illnesses, and Fatalities among Hispanic and Non Hispanic Construction Workers. Journal of Construction Engineering and Management pp. 1021-1028.

16. Brunette MJ (2004) Construction Safety Research in the United States Targeting the Hispanic Workforce. Injury Prevention 10(4): 244-248.

17. Center for Construction Research and Training (CPWR) (2013) Contraction Chart book.

18. Anger WK, Stupfel J, Ammerman T, Tamulinas A, Bodner T, et al. (2006) The Suitability of Computer-Based Training for Workers with Limited Formal Education A Case Study from the US Agricultural Sector. International Journal of Training and Development 10(4): 269-276.

19. Janicak C (2013) Occupational fatalities involving Hispanic workers in he construction industry. Open Journal of Safety Science and Technology 3: 1-7.

20. Greenbaum J, Kyng M (1991) Preface: Memories of the past. Hilldale New Jersey: CRC Press.

21. Spinuzzi C (2005) The methodology of participatory design. Technical Communication 52(2): 163-174.

22. Creswell JW (2009) Research Design Qualitative, Quantitative, and Mixed Methods Approaches. Thousand Oaks California: SAGE Publications.

23. Creswell JW, Plano Clark VL (2007) Designing and conducting mixed methods research. Thousand Oaks CA: Sage. 
24. Noe R (1986) Trainees Attributes and Attitudes: Neglected Influences on Training Effectiveness. Academy of Management Reviews (11): 736-749.

25. Noe RA, Schmitt N (1986) The Influence of Trainee Attitudes on Training Effectiveness: Test of a Model. Personnel Psychology 39(3): 497-523.

26. Salas E, CannonBowser J (2001) The Science of Training: A Decade of Progress. Annual Reviews Psychology 52: pp. 471-499.

27. United States Department of Labor (2012) Occupational Safety and Health Administration.

28. Fox S, Livingston G (2007) Latinos Online Hispanics with lower levels of education and English proficiency remain largely disconnected from the internet. Washington DC Pew Hispanic Center and Pew Internet Project.

29. Nielsen J (2005) Lower-Literacy Users: Writing for a Broad Consumer Audience.

30. Thompson MR (2000) Lights, Camera, Action: Planning Writing \& Producing Employee Education Programs. American Society of Safety Engineers pp. 33-39.

31. Bureau of Labor Statistics United States Department of Labor (2011) Foreign-Born Workers Labor Force Characteristics 2010.

This work is licensed under Creative Commons Attribution 4.0 Licens DOI:10.19080/JOJPH 2017.03.555601
32. Evans CJ, Crawford B (2000) Data Collection Methods in Prospective Economic Evaluations: How Accurate Are the Results? Value in Health $3(4)$.

33. Campbell J, Dunnette M, Lawler E, Weick K (1970) Managerial behavior performance and effectiveness. New York, USA.

34. The Center for Construction Research and Training (2013) The Construction Chart Book $5^{\text {th }}$ edn. Silver Springs MD: The Center for Construction Research and Training.

35. Lipscomb HJ, Schoenfisch AL, Cameron W, Kurcera KL, Adams D, et al. (2014) How well are we controlling fall from height in construction? Experiences of union carpenters in Washington State, 1989-2008. American Journal of Industrial Medicine 57(1): 69-77.

36. Loh K, Richardson S (2004) Foreign born Workers: Trends in Fatal Occupational Injuries, 1996-2001. Monthly Labor Review pp. 42-53.

37. Lopez del Puerto C, Clevenger C, Boreman, K, Gilkey D (2013) An Exploratory Study to Identify Perceptions of Safety Culture and Rish Among Residential Latino Construction Worker as Distinct from Commercial and Heavy Civil. Journal of Construction Engineering and Management 140(2).

38. Medhi I, Sagar A, Toyama K (2007) Text Free User Interfaces for Illiterate and Semiliterate Users. 4(1): 37-50.

\section{Your next submission with Juniper Publishers} will reach you the below assets

- Quality Editorial service

- Swift Peer Review

- Reprints availability

- E-prints Service

- Manuscript Podcast for convenient understanding

- Global attainment for your research

- Manuscript accessibility in different formats

( Pdf, E-pub, Full Text, Audio)

- Unceasing customer service

Track the below URL for one-step submission https://juniperpublishers.com/online-submission.php 